09

\title{
О механизме поглощения и восстановления пропускания излучения в канале мелкомасштабной самофокусировки короткого лазерного импульса в неодимовом стекле
}

\author{
(C) Н.Е. Быковский, Ю.В. Сенатский \\ Физический институт им. П.Н. Лебедева РАН, \\ Москва, Россия \\ ฯE-mail: senatskijyv@lebedev.ru
}

Поступила в Редакцию 10 июня 2019 г.

В окончательной редакции 10 июня 2019 г.

Принята к публикации 17 июня 2019 г.

\begin{abstract}
При диагностике канала мелко-масштабной самофокусировки (МMC) $0.5 \mathrm{~ns}$ лазерного импульса с интенсивностью 3-5 GW/cm ${ }^{2}$ в неодимовых стеклах помимо характерных для ММС нитевидных повреждений в образцах, уширения спектра и рассеяния лазерного излучения был зарегистрирован также скачок поглощения (с фронтом $\approx 0.5 \mathrm{~ns}$ ) излучения на длинах волн 1.06 и $0.66 \mu \mathrm{m}$. Коэффициент поглощения достигал $0.15 \mathrm{~cm}^{-1}$, а восстановление пропускания в среде происходило за время $15-35 \mathrm{~ns}$ для фосфатных и 5-10 ns для силикатных стекол. Физическая картина этого эффекта возникновения и релаксации поглощения в стеклах ранее не была представлена. Проведенный анализ экспериментальных данных показал, что скачок поглощения обусловлен быстрым заселением уровня ${ }^{4} I_{11 / 2}$ ионов $\mathrm{Nd}^{3+}$ в стеклах при протекании в канале ММС нелинейных процессов: ВКР и уширения спектра лазерного импульса. Время релаксации населенности на уровне ${ }^{4} I_{11 / 2}$ и восстановления пропускания в стеклах после окончания лазерного импульса определяются характерными размерами областей возбуждения ионов $\mathrm{Nd}^{3+}$, возникающих в образцах при интерференции лазерного и рассеянного излучения, а также теплофизическими характеристиками стекол.
\end{abstract}

Ключевые слова: неодимовое стекло, мощный лазерный импульс, самофокусировка, наведенное поглощение.

DOI: 10.21883/FTT.2019.11.48419.515

\section{1. Введение}

Физические процессы в оптической среде твердотельных лазеров с короткими и ультракороткими импульсами, работающих в условиях высоких лучевых нагрузок и нелинейного взаимодействия излучения со средой, являются объектом исследований в течение продолжительного времени [1-10]. В работах [4-6] была проведена диагностика канала распространения в неодимовых стеклах мощного импульса (МИ) лазерного излучения (длина волны $\lambda \approx 1.06 \mu \mathrm{m}$, длительность $\approx 0.5 \mathrm{~ns}$ ) с использованием 10-100 ns зондирующих импульсов (ЗИ) небольшой мощности от вспомогательных источников на длинах волн $\lambda_{0}$ и $\lambda_{1}=0.66 \mu \mathrm{m}$. В условиях мелкомасштабной самофокусировки (ММС) основного лазерного пучка с интенсивностью $I=3-5 \mathrm{GW} / \mathrm{cm}^{2}$ помимо характерных для ММС нитевидных повреждений в образцах, уширения спектра и рассеяния излучения с помощью ЗИ был обнаружен также скачок поглощения в стеклах на длинах волн $\lambda_{0}$ и $\lambda_{1}$. Наведенное поглощение (НП) соответствовало переходам с уровня ${ }^{4} I_{11 / 2}$ ионов $\mathrm{Nd}^{3+}$ в стекле на уровни ${ }^{4} F_{3 / 2}$ и ${ }^{2} G_{7 / 2},{ }^{4} G_{5 / 2}$ (см. схему рис. $1[6,8])$ и свидетельствовало о заселении уровня ${ }^{4} I_{11 / 2}$ в среде по трассе распространения МИ. Коэффициент поглощения достигал $0.15 \mathrm{~cm}^{-1}$, фронт нарастания НП составлял $\approx 0.5 \mathrm{~ns}$, а релаксация НП (восстановление пропускания среды в канале ММС) после окончания МИ происходила за времена $\tau_{r}$ в десятки ns [4-6]. Уровень ${ }^{4} I_{11 / 2}$ ионов $\mathrm{Nd}^{3+}$ является нижним уровнем рабочего перехода ${ }^{4} F_{3 / 2}-{ }^{4} I_{11 / 2}$ в стеклах и отделен от штарковских компонент основного уровня ${ }^{4} I_{9 / 2}$ зазором $\approx 1400 \mathrm{~cm}^{-1}$. При комнатной температуре населенность уровня ${ }^{4} I_{11 / 2}$ составляет $\approx 0.01 \%$ от полного числа ионов активатора, и поглощение с этого уровня практически отсутствует. При нагреве стекла населенность уровня ${ }^{4} I_{11 / 2}$ возрастает, достигая $\approx 4 \%$ при $\approx 500^{\circ} \mathrm{C}$, и полосы поглощения на $\lambda_{0}$ и $\lambda_{1}$ легко регистрируются $[6,11,12]$.

Процессы возникновения и релаксации населенности на уровне ${ }^{4} I_{11 / 2}$, которая влияет непосредственно на эффективность работы неодимового лазера, изучались на протяжении длительного времени [6,8,13-18]. Данные о времени $\tau$ безызлучательной релаксации в стеклах с уровня ${ }^{4} I_{11 / 2}$ на нижний уровень ${ }^{4} I_{9 / 2}$ в публикациях 1970-80 гг. были достаточно противоречивы. В нашей работе [6] допускалось, что времена $\tau_{r}$ релаксации НП (восстановления пропускания) в десятки ns соответствуют $\tau$. Значения $\tau$ для стекол, превышающие $10 \mathrm{~ns}$, приводились также в $[8,13]$. В работах [14-16] указывались значения $\tau$ меньшие 2 или $1 \mathrm{~ns}$.

Времена жизни $\tau$ ионов $\mathrm{Nd}^{3+}$ в стеклах и кристаллах на уровне ${ }^{4} I_{11 / 2}$ были корректно измерены при 


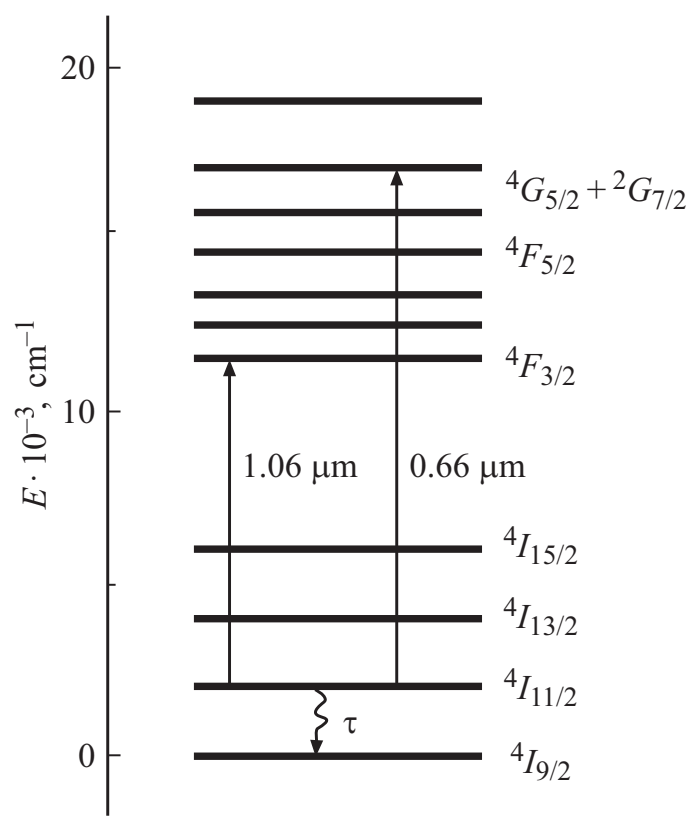

Рис. 1. Упрощенная схема энергетических уровней иона $\mathrm{Nd}^{3+}$ в стекле.

диагностике населенности этого уровня пикосекундными импульсами в [18]. По данным этой работы для фосфатных и силикатных неодимовых стекол время $\tau$ релаксации с уровня ${ }^{4} I_{11 / 2}$ составляет от 200 до $700 \mathrm{ps}$. В тоже время, эксперименты [4-6] свидетельствовали о возникновении под действием МИ на уровне ${ }^{4} I_{11 / 2}$ в стеклах заметной населенности, которая сохранялась в течение времени $\tau_{r}$, на $1-2$ порядка превышающего $\tau$. Механизм возникновения и релаксации этой избыточной населенности и НП, которое свидетельствовало о потерях в лазере на рабочей длине волны $\lambda_{0}$, установлен не был. В настоящей работе представлено объяснение динамики возникновения и релаксации населенности на уровне ${ }^{4} I_{11 / 2}$ ионов $\mathrm{Nd}^{3+}$ и НП в неодимовых стеклах при прохождении через среду $0.5 \mathrm{~ns}$ лазерного импульса высокой интенсивности.

\section{2. Диагностика канала мелкомасштабной самофокусировки лазерного импульса в неодимовом стекле}

Эксперимент в работах [4-6] проводился по схеме рис. 2. В исследуемые образцы стекла (стержни длиной $l=7-26 \mathrm{~cm})$ с выхода лазерной системы на кристаллах $\mathrm{YAG}: \mathrm{Nd}^{3+}$ и неодимовом стекле направлялся МИ с энергией $\approx 0.5 \mathrm{~J}$ при диаметре пучка $\approx 7 \mathrm{~mm}$. Временной профиль МИ на фоторегистраторе „АгатСФ-3“ представлен на рис. 3, $a$, ширина спектра излучения на длине волны $\lambda_{0}$ менее $0.2 \mathrm{~cm}^{-1}$. Лазерный пучок ретранслировался коллиматором (2) в образец с уменьшением, и при диаметре пучка $\approx 2 \mathrm{~mm}$ плотность энергии в образце составляла $2-5 \mathrm{~J} / \mathrm{cm}^{2}$. Энергия МИ на выходе образца измерялась через ирисовую диафрагму 3 с углом регистрации от $10^{-3}$ до $10^{-1} \mathrm{rad}$. Канал прохождения МИ просвечивался под углом $3-5^{\circ}$ ЗИ с длительностями 10-100 ns и энергией $<1 \mathrm{~mJ}$ на линиях $\lambda_{1} \approx 0.66, \lambda_{2} \approx 0.56$ и $\lambda_{0} \approx 1.06 \mu \mathrm{m}$. ЗИ сигнального $\mathrm{S}$ (через образец) и контрольного С каналов, выровненные по интенсивности и временной задержке, фокусировались цилиндрическими линзами перпендикулярно щели фоторегистратора, рис. 2.

НП в образцах определялось по изменениям профиля ЗИ на фоторегистраторе, рис. 4. НП на $\lambda_{1}$ и $\lambda_{0}$ было обнаружено в фосфатных (КНФС, $l=7 \mathrm{~cm}$; ЛГС-55, $l=13 \mathrm{~cm}$, ГЛС-23П, $l=15 \mathrm{~cm})$ и силикатных (ГЛС-1,

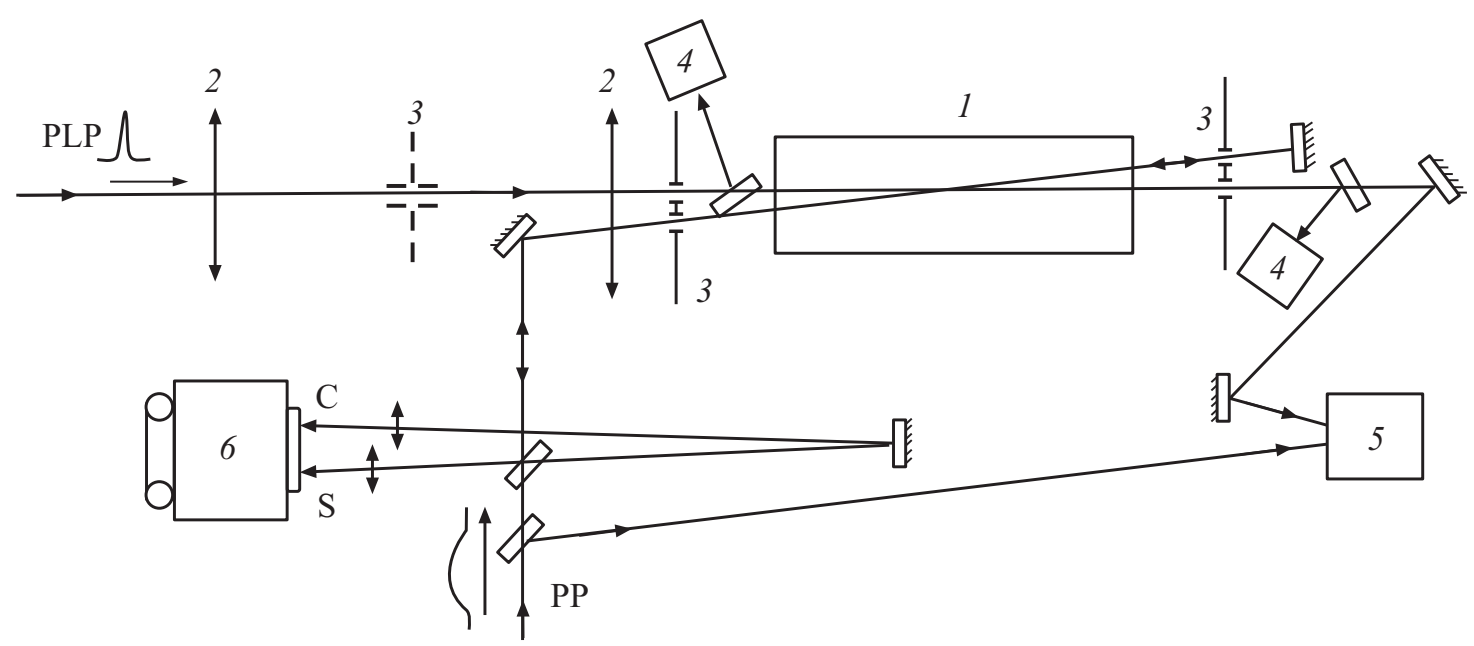

Рис. 2. Схема регистрации наведенного поглощения в образцах неодимовых стекол: 1 - образец; 2 - коллиматор; 3 - диафрагмы; 4 - калориметры; 5 - фотоэлемент; 6 - фоторегистратор „Агат-СФ-3“; PLP - мощный лазерный импульс; PP - зондирующий импульс [5]. 


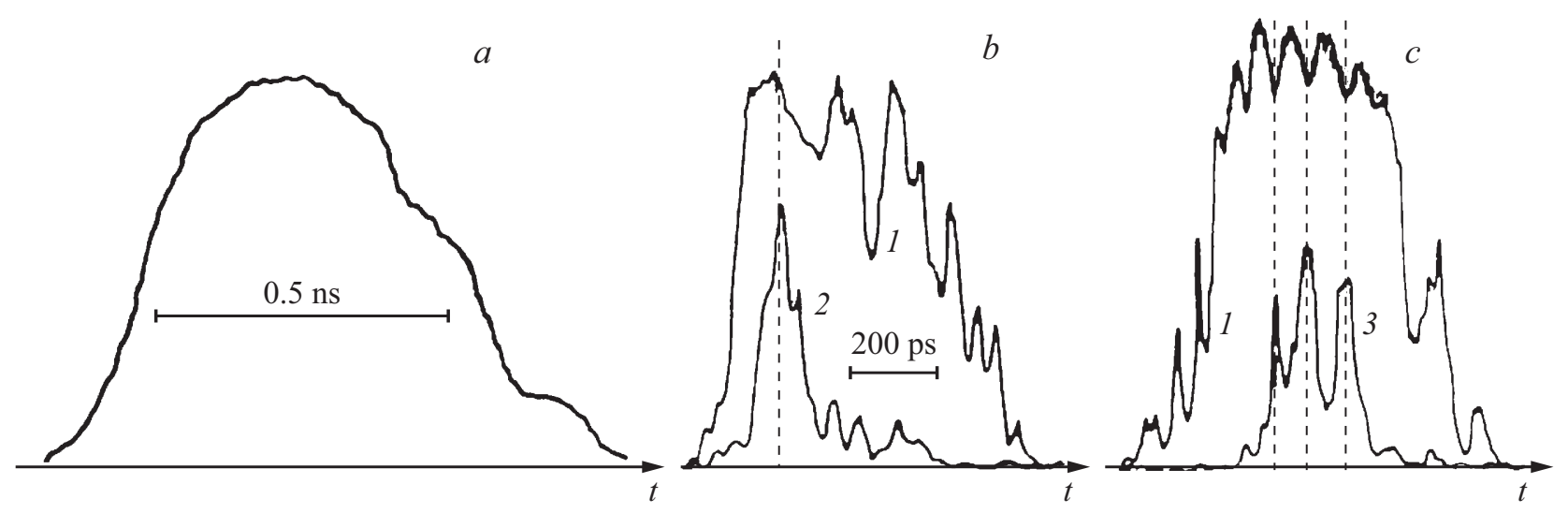

Рис. 3. Денситограммы импульса накачки на входе в образец $(a)$, прошедших через образец импульсов $(b, c$, кривые 1$)$ и импульсов рассеяния $(b, c)$ на длине волны 1.217 (2) и $1.064 \mu \mathrm{m}(3)[6,7]$.
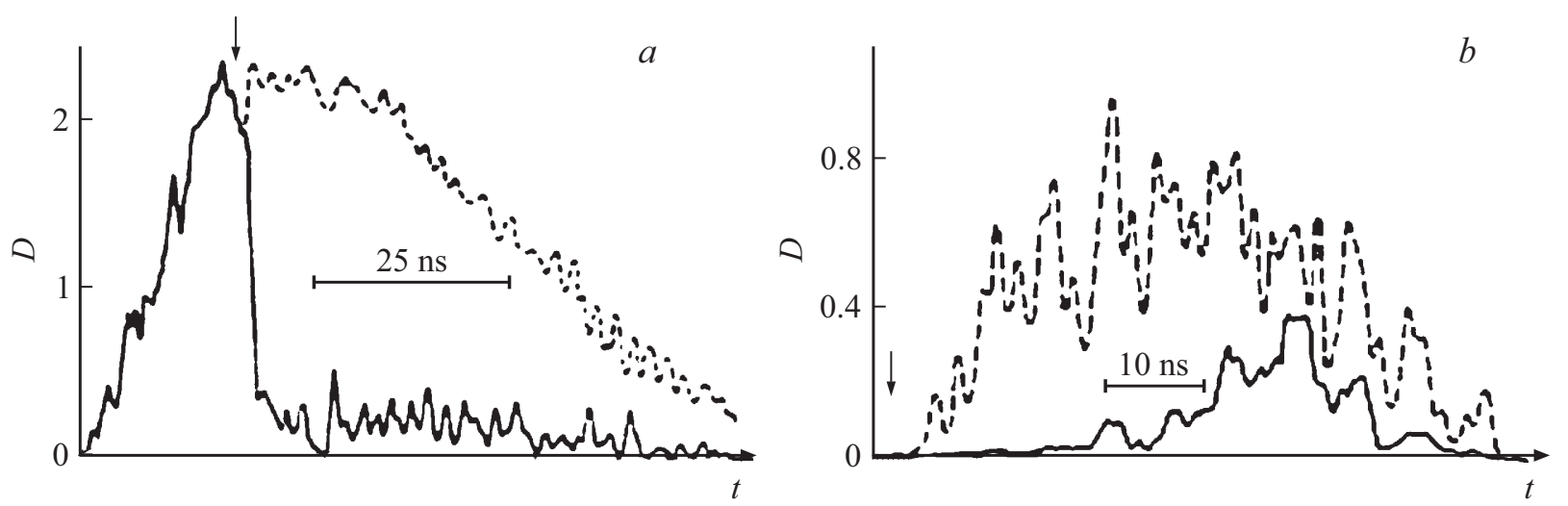

Рис. 4. Денситограммы ЗИ на $\lambda_{1}=0.66 \mu \mathrm{m}$ контрольного (пунктир) и сигнального (сплошные линии) каналов для образцов из стекла КНФС $(a)$ и ЛГС-55 $(b)$. Стрелками указан момент прихода МИ в образец [6].

$l=26 \mathrm{~cm}$; ГЛС-4, $l=16 \mathrm{~cm})$ стеклах. НП носило пороговый характер, возникало при плотностях мощности МИ более $3 \mathrm{GW} / \mathrm{cm}^{2}$ в фосфатных и более $5 \mathrm{GW} / \mathrm{cm}^{2}$ в силикатных стеклах и всегда сопровождалось появлением нитевидных повреждений в стекле. При малых интенсивностях МИ нити появлялись у выходного торца образцов, с ростом энергии нити (10-15 штук) заполняли почти всю длину канала МИ. Потери МИ на рассеяние за пределы коллимированного лазерного пучка на углы до $0.1 \mathrm{rad}$ достигали $40 \%$ падавшей на образец энергии. Скачок поглощения во всех стеклах имел передний фронт, определяемый временем $(0.5-1.5 \mathrm{~ns})$ прохода ЗИ через образец, рис. 4, $a$. Усредненное по длине образца поглощение для $\lambda_{1}$ достигало в фосфатных стеклах величины $\alpha_{1} \approx 0.15 \mathrm{~cm}^{-1}$, а для $\lambda_{0}$ $\alpha_{0} \approx 0.05 \mathrm{~cm}^{-1}$. В силикатных стеклах $\alpha_{1} \leq 0.03 \mathrm{~cm}^{-1}$, $\alpha_{0}<0.01 \mathrm{~cm}^{-1}$. Меньшие значения НП для $\lambda_{0}$ соответствовали отношению $\approx 2: 1$ сечений поглощения с уровня ${ }^{4} I_{11 / 2}$ для $\lambda_{1}$ и $\lambda_{0}$ в стеклах [11]. Релаксация НП в фосфатных стеклах происходила за время $\tau_{r}=15-35 \mathrm{~ns}$. Для силикатных стекол наблюдались меньшие значения $\tau_{r}=5-10 \mathrm{~ns}[4-6,17]$. НП не было зарегистрировано для ЗИ с $\lambda_{2} \approx 0.56 \mu \mathrm{m}$ (нерезонансной для уровня ${ }^{4} I_{11 / 2}$ ), а также в стеклах К-8, ГЛС-1 (без активатора) и др., что указывает на связь НП с ионами $\mathrm{Nd}^{3+}$. Этот вывод подтверждается также зависимостью НП от концентрации ионов $\mathrm{Nd}^{3+}[6,17]$.

В работе [7] в тех же, что и в экспериментах [4-6] условиях была проведена регистрация временного профиля и спектров излучения на выходе образцов из стекла при ММС МИ. Во всех неодимовых стеклах и стеклах без активатора было зарегистрировано сверхуширение $(\mathrm{CУ})$ спектра прошедшего образцы лазерного излучения, рис. 5. В стекле К-8 $(l=13 \mathrm{~cm})$ СУ достигало $2000 \mathrm{~cm}^{-1}$. В Li-La-Nd-фосфатном стекле КНФC $\left(l=7 \mathrm{~cm}\right.$, концентрация $\left.\mathrm{Nd}^{3+} N_{0}=8 \cdot 10^{20} \mathrm{~cm}^{-3}\right)$ при $I \geq 3 \mathrm{GW} / \mathrm{cm}^{2}$ наряду со СУ $\left(>1000 \mathrm{~cm}^{-1}\right)$ была зарегистрирована линия ВКР с $\lambda_{s}=1.217 \mu \mathrm{m}$, рис. 5. Стоксов сдвиг линии $\approx 1180 \mathrm{~cm}^{-1}$ соответствовал фононному пику колебаний фосфатных тетраэдров $\mathrm{PO}_{4}$-группы $[7,17]$.

Для анализа временного профиля импульсов, прошедших образец и диафрагму 3, излучение фокусировалось на щель прибора „Агат-СФ-3“. Подбором фильтров выделялось излучение только на длине волны $\lambda_{0}$, только линия ВКР или одновременно импульсы накачки и рассеяния. На профиле прошедшего образец лазерного 
импульса видны провалы интенсивности из-за выброса части излучения на большие углы, рис. $3, b, c$. Глубина модуляции профиля достигала $30-80 \%$ и приводила к разбиению импульса на субимпульсы длительностью 100-150 ps. Временное расположение провалов на профиле МИ скоррелировано с выбросами рассеянного излучения на длине волны $\lambda_{0}$, рис. $3, c$. Наблюдалось несколько импульсов ВКР длительностью 80-120 ps, рис. $3, b$. Эти импульсы были скоррелированы с максимумами на профиле накачки, после которых интенсивность накачки спадала за счет перекачки энергии в ВКР, рис. $3, b$.

\section{3. Механизм возникновения и релаксации наведенного поглощения в канале мелко-масштабной самофокусировки лазерного импульса в неодимовом стекле}

Селективные свойства НП и его отсутствие в стеклах без неодима свидетельствуют о возбуждении в канале ММС лазерного импульса в силикатных и фосфатных неодимовых стеклах уровня ${ }^{4} I_{11 / 2}$ ионов $\mathrm{Nd}^{3+}$ [4-6]. Возбуждение ионов происходило за счет энергии МИ, переданной среде. В работе [6] приведены оценки населенности, возникавшей на уровне ${ }^{4} I_{11 / 2}$ во время прохождения МИ, и энергии, затраченной на возбуждение ионов $\mathrm{Nd}^{3+}$ в стекле КНФС $\left(l=7 \mathrm{~cm}, N_{0}=8 \cdot 10^{20} \mathrm{~cm}^{-3}\right)$. Если считать, что НП $\left(\lambda_{0}=0.05 \mathrm{~cm}^{-1}\right)$ в КНФС относится ко всему объему V канала МИ с Ø $2.2 \mathrm{~mm}$, а сечение перехода ${ }^{4} I_{11 / 2}-{ }^{4} F_{3 / 2} \quad \sigma=3.8 \cdot 10^{-20} \mathrm{~cm}^{2}$, то для усредненной неравновесной плотности населенности $N_{11 / 2}$ на уровне ${ }^{4} I_{11 / 2}$ в канале получаем $N_{11 / 2}=\alpha_{0} / \sigma=1,3 \cdot 10^{18} \mathrm{~cm}^{-3}$.

Учитывая, что для перехода ${ }^{4} I_{9 / 2}-{ }^{4} I_{11 / 2} \quad h v \approx$ $\approx 4 \cdot 10^{-20} \mathrm{~J}$, для энергии $\varepsilon$, затраченной на возбуждение ионов $\mathrm{Nd}^{3+}$ в канале,

$$
\varepsilon=h v \cdot \alpha_{0} V / \sigma
$$

получаем оценку $\varepsilon \approx 12 \mathrm{~mJ}$.

Поскольку НП наблюдалось в условиях ММС, то можно было предполагать локализацию НП в участках среды с повышенной интенсивностью вдоль траекторий „бегущего фокуса“. В работе [19], например, при самофокусировке ps импульсов при интенсивностях, близких к нашим экспериментам [4-7], СУ спектра лазерного излучения в стеклах (до $4000 \mathrm{~cm}^{-1}$ в стоксовой области) наблюдалось в филаментах Ø 20-50 $\mu \mathrm{m}$. Оценки, однако, показывают, что объяснить наблюдавшийся в наших работах эффект НП поглощением только в структуре из 10-15 филаментов Ø 20-50 $\mu \mathrm{m}$ вдоль траекторий „бегущего фокуса“, объем которых на 2-3 порядка меньше объема $V$ канала распространения МИ, не представляется возможным.
Ниже приводится феноменологическое описание процессов в канале ММС МИ, которое позволяет объяснить возникновение и релаксацию НП в неодимовых стеклах при распространении мощного лазерного импульса. Из данных эксперимента [4-6] следует, что НП возникало в образцах за время действия $(\approx 0.5 \mathrm{~ns})$ МИ, а релаксация НП происходила после окончания МИ. Рассмотрим вначале процессы, приводящие к заселению уровня ${ }^{4} I_{11 / 2}$. Выделение энергии, необходимой для заселения этого уровня, происходило в канале ММС МИ вследствие нелинейных процессов с трансформацией спектра лазерного излучения (накачки). Такими процессами в соответствии с данными эксперимента (рис. 5) могли быть сверхуширение спектра и комбинационное рассеяние накачки. Вклад СУ в НП мог происходить по следующей схеме. При СУ свыше $3000 \mathrm{~cm}^{-1}$ излучение в стоксовой части спектра в области $1.6 \mu \mathrm{m}$ могло поглощаться ионами $\mathrm{Nd}^{3+}$ в результате переходов с основного уровня ${ }^{4} I_{9 / 2}$ на уровень ${ }^{4} I_{15 / 2}$ с последующим быстрым (за сотни ps [18]) переходом ионов на уровень ${ }^{4} I_{11 / 2}$. Экспериментального подтверждения такого процесса заселения уровня ${ }^{4} I_{11 / 2}$, однако, не было получено, поскольку диапазон регистрации СУ в стоксовой части спектра в работах [4-6] ограничивался (до $\approx 1.3 \mu \mathrm{m})$ чувствительностью фотопленки.

Комбинационное рассеяние лазерного излучения на колебаниях $\mathrm{PO}_{4}$ и $\mathrm{SiO}_{4}$-групп в неодимовых стеклах было определено Ю.П. Рудницким с соавторами в качестве причины возникновения избыточной населенности на уровне ${ }^{4} I_{11 / 2}$ ионов $\mathrm{Nd}^{3+}$ при распространении в этих стеклах $40 \mathrm{~ns}$ импульсов с плотностью энергии до $10 \mathrm{~J} / \mathrm{cm}^{2}$ в экспериментах [14]. Комбинационное рассеяние излучения накачки могло обеспечить выделение энергии в матрице стекла в канале распространения МИ с последующей передачей возбуждения на ионы $\mathrm{Nd}^{3+}$ и в наших экспериментах [4-6]. В условиях ММС в образцах стекла могло возбуждаться ВКР накачки. При многофотонном поглощении излучения накачки вдоль треков ММС возникали ионизованные атомы, и в среде, окружавшей образовавшиеся ионы и электроны, за счет резкого изменения внутрикристаллических полей происходило ударное возбуждение широкого спектра колебаний окружающих атомов, вплоть до оптических частот. Можно предположить, что эти колебания служили затравкой для развития на них ВКР накачки в широкой области спектра с выделением в матрице стекла энергии и последующим возбуждением ионов $\mathrm{Nd}^{3+}$. В пользу этого механизма возбуждения говорит наблюдение линии комбинационного рассеяния на длине волны $\lambda_{s}$ и направленность рассеяния на выходе образцов, рис. 5. Отметим, что ионизация возбуждает высокоэнергетичные фононы сразу с большой амплитудой, что могло позволить развиваться ВКР даже при малом коэффициенте усиления. То, что НП было связано с ионизацией среды, подтверждается характером зависимости порога НП от интенсивности для разных стекол: для силикатных стекол, где ширина запрещенной зоны (до $6 \mathrm{eV}$ ) больше, чем у фосфатных стекол [8], выше оказался и порог наблюдения НП. 

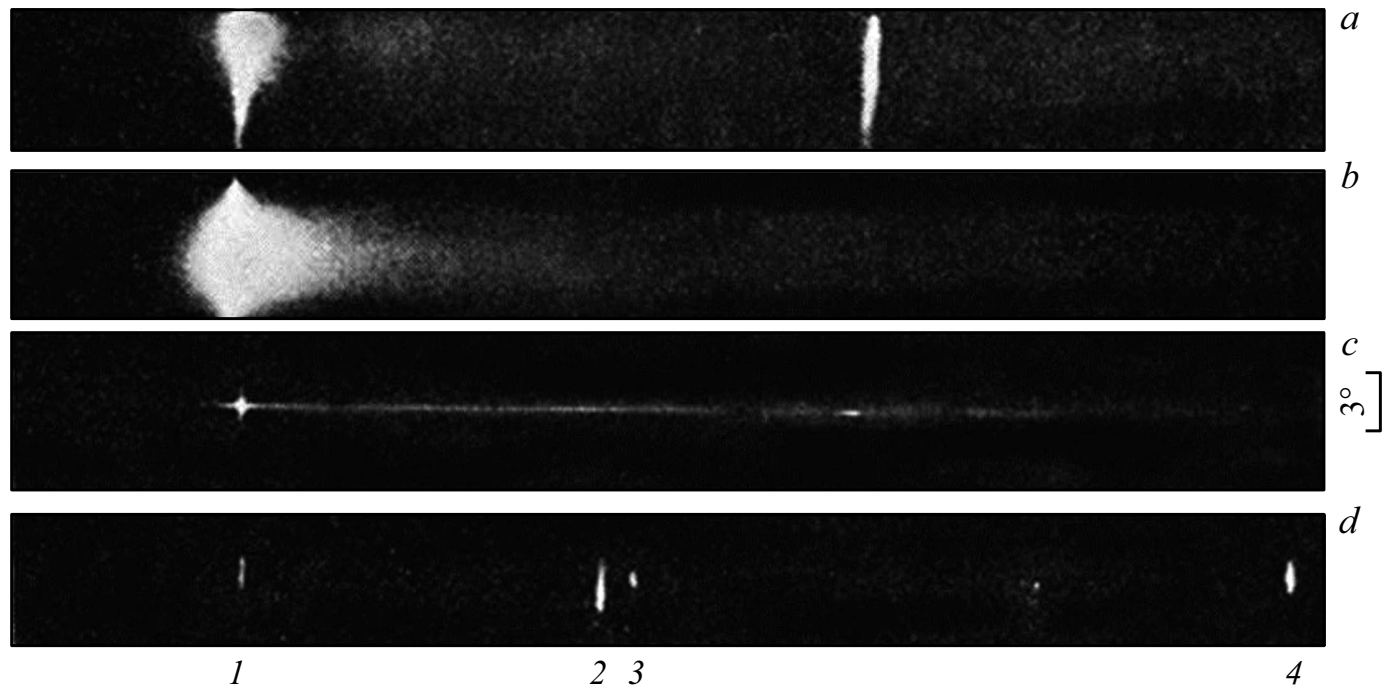

Рис. 5. Спектры излучения, прошедшего через образцы (за 1 вспышку): (a,c) Li-La-Nd-фосфатное стекло без фокусировки (a) и при фокусировке $(c)$ на щель; $(b)$ стекло ЛГС-55; $(d)$-калибровочные линии YAG : $\mathrm{Nd}^{3+}$ лазера $1.064 \mu \mathrm{m}(1)$ и $1.318 \mu \mathrm{m}(4)$ и Не-Nе-лазера $1.152 \mu \mathrm{m}(2)$ и $1.160 \mu \mathrm{m}(3)$ [7].

Рассеяние от цепочки первичных очагов возбуждения вдоль нитей, распространяясь под углами синхронизма и интерферируя с накачкой, формировало в среде пространственную структуру из большого числа максимумов и минимумов интенсивности. В максимумах возникали вторичные очаги колебаний решетки, рассеяние на которых волны накачки с трансформацией спектра приводило к дополнительному выделению энергии в среде и возбуждению новых ионов $\mathrm{Nd}^{3+}$. Ионы $\mathrm{Nd}^{3+}$ могли возбуждаться не только на уровень ${ }^{4} I_{11 / 2}$, но и на вышележащие уровни мультиплета ${ }^{4} I$ (рис. 1), откуда происходила их релаксация на ${ }^{4} I_{11 / 2}$. Таким образом, вследствие интерференции накачки с рассеянным и сдвинутым по спектру излучением центрами возбуждения заполнялся практически весь объем канала. Возникавшая за $\approx 0.5 \mathrm{~ns}$ населенность на уровне ${ }^{4} I_{11 / 2}$ в образцах стекол диагностировалась с помощью ЗИ как скачок поглощения на длинах волн $\lambda_{0}$ и $\lambda_{1}$.

Времена жизни самых высокочастотных колебаний решетки составляют пикосекунды, но за счет их раскачки излучением накачки и развития новых очагов возбуждения высокочастотные колебания наряду с фононами меньшей энергии генерировались в канале МИ на протяжении всего импульса накачки, поддерживая ВКР. Хотя в работах [4-7,17] детальные исследования спектрально-угловых характеристик рассеяния произведены не были, можно предположить, что наблюдавшееся под углами до $5^{\circ}$ рассеяние содержало компоненту ВКР, которая составляла заметную долю в энергии рассеянного излучения. ВКР вносило, по-видимому, вклад и в формирование широкополосных спектров прошедшего образцы излучения, рис. 5. Отметим, что развитие ВКР ns импульсов в кристалле $\mathrm{Yb}: \mathrm{YAG}$ и иттербиевом стекле описано в $[20,21]$.

После окончания МИ населенность на уровне ${ }^{4} I_{11 / 2}$ уменьшалась за время $\tau_{r} \gg \tau$ вследствие тепловой ре- лаксации нагретых областей, что диагностировалось как спад НП. Принимая значения $\tau_{r}$ за время релаксации областей выделения тепла в стекле и используя известное соотношение, связывающее $\tau_{r}$ с размером области $r$ и коэффициентом температуропроводности среды $\varkappa$ [22],

$$
\tau_{r}=r^{2} / \varkappa,
$$

можно, зная $\varkappa$ и значения $\tau_{r}$ для фосфатных и силикатных стекол из эксперимента [4-6], оценить характерные размеры областей выделения тепла. Из сопоставления данных публикаций по коэффициентам $\varkappa$ для фосфатных и силикатных стекол [8,23-26] следует общий вывод, что для силикатных стекол значения $\varkappa$ в $2-3$ раза выше, чем для фосфатных. Так для силикатного стекла БК-7 $\varkappa \approx 0.55 \mathrm{~mm}^{2} / \mathrm{s}[25,26]$, для ГЛС-1 $\varkappa \approx 0.53 \mathrm{~mm}^{2} / \mathrm{s}[8,23]$, а для плавленого кварца $\varkappa$ достигает $\approx 0.9 \mathrm{~mm}^{2} / \mathrm{s}[25]$. Для фосфатных лазерных стекол отечественных и зарубежных марок ЛГС-55, ГЛС-22, Q-98, LG-750 значения $\varkappa$ составляют $0.2-0.3 \mathrm{~mm}^{2} / \mathrm{s}[8,23,24]$. Различия в значениях $\varkappa$ объясняют наблюдавшиеся в [4-6] различия в скорости релаксации НП в силикатных и фосфатных стеклах.

Подставляя в формулу (2) данные по $\varkappa$ и значения $\tau_{r}$ для силикатных и фосфатных стекол, мы получаем для характерного размера области тепловыделения и в фосфатных, и в силикатных стеклах оценку $r \leq 100 \mathrm{~nm}$. Такие малые участки тепловыделения соответствуют представленной выше картине интерференции излучения накачки с рассеянным излучением в канале распространения МИ и действительно могли сформироваться в максимумах интерференции. Структура центров тепловыделения должна была, по существу, отражать пространственную картину биений несущей волны (накачки) с наиболее интенсивными стоксовыми компонентами рассеяния с различными направлениями распространения и длинами волн. Хотя шаг такой структуры связан с 
длиной волны накачки ( $\left.\lambda_{0} \approx 1 \mu \mathrm{m}\right)$, картина распределения центров тепловыделения по сечению и длине канала была, скорее всего, нерегулярной. Очаги тепловыделения были окружены более холодными участками среды, в результате теплообмена с которыми и происходило их охлаждение. Динамика нагрева и охлаждения пространственной структуры из мелких очагов тепловыделения в канале прохождения МИ и определяла, по-видимому, наблюдавшуюся в экспериментах [4-6] динамику НП. Для оценки параметров этой структуры, сориентированной вдоль пучка накачки, можно предположить, что канал МИ был заполнен вдоль этого направления центрами тепловыделения с характерными размерами $r \approx 100 \mathrm{~nm}$ с коэффициентом заполнения 0.2 (по 2 „горячих“ центра на период волны накачки $\left.\lambda_{0} \approx 1 \mu \mathrm{m}\right)$. В этом случае, считая в (1) энергию возбуждения $\varepsilon$ фиксированной, для плотности населенности в центрах возбуждения в стекле КНФС получаем значение $N_{11 / 2}=6.5 \cdot 10^{18} \mathrm{~cm}^{-3}$ и $\alpha_{0}=0.25 \mathrm{~cm}^{-1}$.

\section{4. Заключение}

Скачок поглощения излучения в неодимовых стеклах при распространении мощного короткого лазерного импульса был обнаружен в 1980-х годах [4-6]. Однако, физическая картина этого явления не была представлена. Проведенный анализ данных работ [4-7] показал, что наблюдавшийся скачок поглощения в стеклах на длинах волн $\lambda_{0}=1.06 \mu \mathrm{m}$ и $\lambda_{1}=0.66 \mu \mathrm{m}$ обусловлен быстрым $(\approx 0.5 \mathrm{~ns})$ заселением уровня ${ }^{4} I_{11 / 2}$ ионов $\mathrm{Nd}^{3+}$ при нелинейных процессах (ВКР и уширении спектра лазерного излучения) в канале мелкомасштабной самофокусировки лазерного импульса в среде. Скорость релаксации населенности на уровне ${ }^{4} I_{11 / 2}$ и время восстановления пропускания в стеклах (5-35 ns) определяются характерными размерами областей возбуждения ионов $\mathrm{Nd}^{3+}$, возникающих в образцах при интерференции лазерного и рассеянного излучения, и теплофизическими характеристикам фосфатных и силикатных стекол. Таким образом, данные по времени релаксации наведенного поглощения в неодимовых стеклах, приводившиеся в [46], дают информацию не о времени жизни ионов $\mathrm{Nd}^{3+}$ на уровне ${ }^{4} I_{11 / 2}$ (как считалось в [4-6]), а о времени тепловой релаксации областей возбуждения ионов $\mathrm{Nd}^{3+}$ в среде. Рассмотренная модель возникновения и релаксации наведенного поглощения в неодимовых стеклах при самофокусировке короткого светового импульса дополняет картину физических процессов, которые могут протекать в активной среде мощного неодимового лазера. Проявление подобного эффекта возможно и в других твердотельных лазерных средах, например в стеклах и кристаллах, активированных иттербием.

\section{Финансирование работы}

Работа выполнена при поддержке гранта РФФИ № 18-02-00285.

\section{Конфликт интересов}

Авторы заявляют, что у них нет конфликта интересов.

\section{Список литературы}

[1] Н.Е. Быковский, Н.Б. Баранова, Б.Я. Зельдович, Ю.В. Сенатский. Квантовая электрон. 1, 2435 (1974).

[2] J.A. Fleck, Jr., J.R. Morris, E.S. Bliss. IEEE J. Quantum Electron. QE-14, 353 (1978).

[3] N.B. Baranova, N.E. Bykovsky, S.V. Tchekalin, Yu.V. Senatsky. J. Soviet Laser Res. 1, 53 (1980).

[4] V.V. Ivanov, Yu.V. Senatsky, G.V. Sklizkov. Phys. Lett. A 124, 381 (1987).

[5] В.В. Иванов, Ю.В. Сенатский, Г.В. Склизков. Письма в ЖЭТФ 45, 410 (1987).

[6] Н.Е. Быковский, В.В. Иванов, Ю.В. Сенатский, Г.В. Склизков. Квантовая электрон. 15, 1240 (1988).

[7] В.В. Иванов, Ю.В. Сенатский, Г.В. Склизков. Письма в ЖЭТФ 47, 80 (1988).

[8] А.А. Мак, Л.Н. Сомс, В.А. Фромзель, В.Е. Яшин. Лазеры на неодимовом стекле. Наука, М. (1990). 288 с.

[9] S.G. Lukishova, Yu.V. Senatsky, N.E. Bykovsky, A.S. Scheulin. Beam Shaping and Suppression of Self-Focusing in HighPeak-Power Nd: Glass Laser Systems / „Self-focusing: Past and Present. Fundamentals and Prospects" Springer Series: Topics in Applied Physics 114, (2009). P. 191.

[10] С.В. Чекалин, В.П. Кандидов. УФН 183, 133 (2013).

[11] R.A. Fisher, L.T. James Opt. Commun. 13, 402 (1975).

[12] Л.Е. Агеева, Н.Б. Брачковская, С.Г. Лунтер, А.К. Пржевуский, М.Н. Толстой. Квантовая электрон. 4, 2414 (1977).

[13] А.А. Мак, Д.С. Прилежаев, В.А. Серебряков, А.Д. Стариков. Оптика и спектроскопия 33, 689 (1972).

[14] Ю.П. Рудницкий, Р.В. Смирнов, В.М. Черняк. Квантовая электрон. 3, 2035(1976).

[15] W.E. Martin, D. Milam. IEEE J. Quantum Electronics QE-18, 1155 (1982).

[16] В.Н. Алексеев, Д.И. Дмитриев, А.Н. Жилин, В.Н. Чернов. Квантовая электрон. 12, 159 (1985).

[17] В.В. Иванов. Дисс. канд.наук ФИАН, М. (1988).

[18] C. Bibeau, S. Payne, H. Powell. J. Opt. Soc. Am. B, 12, 1981 (1995).

[19] R.R. Alfano, S.L. Shapiro. Phys. Rev. Lett. 24, 592 (1970).

[20] N.E. Bykovsky, E.V. Zavedeev, V.G. Ralchenko, Yu.V. Senatsky. Laser Phys. Lett. 12, 056102 (2015).

[21] N.E. Bykovskii, E.V. Zavedeev,Yu.V. Senatskii. Phys. Solid State 57, 798 (2015).

[22] Л.Д. Ландау, Е.М. Лифшиц. Теоретическая физика. Т. VI. Гидродинамика, Наука, Физматлит М: (1988). 736 с.

[23] Л.И. Авакянц, И.М. Бужинский, Е.И. Корягина, В.Ф. Суркова. Квантовая электрон. 5, 725 (1978).

[24] D. Messias, C. Jacinto, M. Bell, T. Catunda. IEEE J. Quantum Electron. QE-43, 751 (2007).

[25] S. Balachandar, N.C. Shivaprakash, L. Kameswara Rao. Pramana. J. Phys. 88, 41 (2017).

[26] L. Kubicar, V. Vretenar, U. Hammerschmidt. Int. J. Thermophysics 26, 507 (2005).

Редактор К.В. Емцев 